\title{
A REFORMA DA EDUCAÇÃO COMO PERÍCIA: QUESTÕES DO FAZER ADMINISTRATIVO NOS ANOS 1920
}

\author{
André Luiz Paulilo \\ Universidade Estadual de Campinas, Brasil.
}

Resumo

O principal objetivo deste texto é analisar como Carneiro Leão e Fernando de Azevedo administraram a Diretoria Geral de Instrução Pública do Distrito Federal. Ele se atém à idéia de que as reformas da educação escolar da cidade do Rio de Janeiro não foram exatamente o resultado de esquemas institucionais definidos. Em razão disso, o esforço de pesquisa vai no sentido de compreender algo do que significou dirigir a instrução pública da capital do país naquele período. O ponto central da discussão diz respeito ao modo como a educação pública do Distrito Federal foi administrada nos anos 1920.

Palavras-chave: reforma da educação, administração pública, escola, Carneiro Leão e Fernando de Azevedo.

\section{THE REFORM OF EDUCATION AS EXPERTISE: MAKE ADMINISTRATIVE ISSUES IN THE 20 YEARS}

Abstract

The main purpose of this paper is to analyze how Carneiro Leão and Fernando de Azevedo managed the Directorate of Public Instruction of the Federal District. It discusses the idea that the reforms of school education in the city of Rio de Janeiro were not exactly the result of institutional arrangements defined. For this reason, the research effort goes toward understand something of what meant driving public education capital of the Brazil during that time. The focus of discussion is the way public education in the Federal District was administered in 1920' years.

Key-words: Reform of education, public administration, school, Carneiro Leão and Fernando de Azevedo.

\section{LA REFORMA EDUCATIVA COMO EXPERIENCIA: PROBLEMAS EN LA DÉCADA DE 1920 DEL HACER ADMINISTRATIVO}

\section{Resumen}

El objetivo principal de este trabajo es analizar cómo la Dirección General de Instrucción Pública del Distrito Federal fuera administrada por Carneiro Leão y Fernando de Azevedo. Se aferra a la idea de que las reformas de la educación escolar en la ciudad de Río de Janeiro no eran

\begin{tabular}{|c|c|c|c|c|c|}
\hline Hist. Educ. [Online] & Porto Alegre & v. 17 & n. 41 & Set./dez. 2013 & p. 43-57 \\
\hline
\end{tabular}


precisamente el conjunto de resultados de los arreglos institucionales. Como resultado, los esfuerzos de investigación hacia la comprensión de que significaba conducir la educación pública del capital del país en ese período. El punto focal de las preocupaciones de discusión es cómo se administró la educación pública del Distrito Federal en los años 1920.

Palabras clave: reforma de la educación, gobierno, escuela, Carneiro Leão y Fernando de Azevedo.

\section{REFORME DE L'EDUCATION COMMENT EXPERTISE: PROBLEMES ADMINISTRATIF DANS LES ANNEES 1920}

Résume

L'objectif principal de cet article est d'analyser comment la Direction générale de I'Instruction Publique du District Fédéral été administré pour Carneiro Leão et Fernando de Azevedo. II s'accroche à l'idée que les réformes de l'éducation scolaire dans Rio de Janeiro n'étaient pas exactement le jeu de résultats d'arrangements institutionnels. En conséquence, l'effort de recherche est à comprendre quelque chose qui signifiait la conduite d'enseignement public du pays pendant cette période. Le point focal de discussion concerne la façon dont l'enseignement public du district fédéral a été administré dans les années 1920.

Mots-clé: réforme de l'éducation, administration publique, scolaires, Carneiro Leão et Fernando de Azevedo 


\section{$O$ apelo do real}

o publicar, em 1926, O ensino na capital do Brasil, Carneiro Leão esclareceu
muito bem o que pensava ser importante numa reforma do ensino público do
Distrito Federal. Sobretudo, considerou o caráter social e político das reformas da instrução pública quando escreveu acerca das tarefas da direção do ensino. Tanto para solucionar o problema da nacionalização do elemento estrangeiro numa capital cosmopolita como era o Rio de Janeiro, quanto para dar-lhe um maior rendimento escolar, Carneiro Leão (1926) observou que era fundamental atrair as classes pobres à escola e, assim, enchê-las de crianças.

Para ele, contudo, a finalidade da administração do ensino não era apenas atrair para a escola, mas "pela direção dos elementos mais delicados, conquistar definitivamente da criança a boa disposição e o amor pelo meio escolar, garantindo a frequência mais tarde nos demais anos do curso" (Carneiro Leão, 1926, p. 9-10). As providências nesse sentido, Carneiro Leão julgava ser de ordem social. Assim, assumiu as iniciativas de aproximação da escola com o meio familiar e social, a defesa da saúde na escola, a organização da assistência escolar e a generalização da educação física como meios de conservar a frequência das crianças nas aulas (Carneiro Leão, 1926).

O posicionamento de Carneiro Leão acerca do que significava dirigir a educação pública informa sobre decisões significativas. Em O ensino na capital do Brasil fica clara a preocupação de Carneiro Leão com o aumento dos anos escolares e da escolarização das massas operárias brasileiras. Ele assumiu que era dever da direção da instrução buscar a causa do êxodo da população dos bancos escolares para remediar o mal, em vez de limitar a dois anos o ensino elementar, porque daí somente uma percentagem pequena de crianças freqüentava a escola (Ibid.).

Opôs-se, então, contra aqueles que propugnavam pela supressão do curso primário complementar, sendo contrário às insinuações de que caso as professoras desses cursos estivessem ocupadas em alfabetizar, o problema do analfabetismo encontraria solução (Carneiro Leão, 1926). Igualmente, Carneiro Leão combateu a ideia da eliminação ou da distinção pelo ouro das crianças abastadas nas escolas públicas. Achava mesmo equivocado o argumento de que a gente rica da cidade vivia a tomar o lugar dos pobres nas escolas públicas. Assim, perguntando quem, de fato, poderia pagar pelo ensino, concluiu não só pela necessidade da gratuidade do ensino público mas, também, pela importância do auxílio assistencial para as crianças. Ainda foi parte do esforço para ampliar o alcance das escolas públicas, o envio de muitos professores adjuntos das áreas centrais da cidade para os subúrbios.

Carneiro Leão diz ter trabalhado por uma distribuição mais equitativa do professorado, com vistas a prover as escolas onde os serviços educativos eram reclamados com mais urgência. Noutro sentido, buscou atrair para a escola as crianças analfabetas, ao conferir um merecimento maior aos docentes que conseguissem melhores resultados no primeiro ano (Carneiro Leão, 1926). Com essa medida, a Diretoria de Instrução reforçou o propósito de "conquistar definitivamente da criança a boa disposição e o amor pelo meio escolar" (p. 9-10), avaliando vantajosamente as professoras de $1^{3}$ série que assegurassem dos seus alunos uma percentagem de frequência maior de 75. Enfim, Carneiro Leão sublinhou, nas iniciativas da Diretoria Geral 
de Instrução Pública em prol da criança, a renovação dos métodos de ensino. Segundo o seu entendimento, a questão era técnica e implicava integrar a escola nas realidades correntes, "tirá-la da margem da vida, fazendo a vida de todos os dias circular nas suas classes" (lbid., p. 42).

Em vista dessa orientação, as ideias acerca de um ensino essencialmente experimental, de uma preparação baseada na observação e na experiência, encontraram um emprego hábil nos relatos de $O$ ensino na capital do Brasil. A percepção da educação como o resultado da atitude da escola diante da vida e das exigências sociais presentes e futuras, fazia Carneiro Leão atento às finalidades sociais que a instrução pública podia cumprir. Sobretudo, tratou-se de mostrar que a escola tinha a função de trazer a vida à vista das crianças. Nesse sentido, Carneiro Leão mostrou querer que o pensamento fosse educado nas escolas para estudar e ajudar a construir a realidade em proveito do meio social.

No entanto, efetivamente, o apelo do real, das questões sociais e nacionais, tão evidentes em Carneiro Leão quando dirigiu a instrução pública do Distrito Federal, acompanhava mais que o administrador, o publicista. A preocupação com a instrução popular no Brasil vinha desde 1909 quando fez, no Ginásio São Bento, em São Paulo, por ocasião de um congresso de estudantes, uma conferência de educação. Ela foi ampliada e publicada meses depois, dando origem ao volume Educação.

Desde então não deixou mais de tratar do tema, escrevendo constantemente para os jornais artigos de propaganda da educação. Seguiram-se ainda viagens ao Ceará em 1913 e, no ano seguinte, à Paraíba e para Pernambuco, com a finalidade de combate e de crítica ao atraso educativo do país. Carneiro Leão voltou ao assunto na série de conferências pronunciadas em 1915 na Biblioteca Nacional, no Rio de Janeiro, e na Escola Normal de São Paulo, em 1916. No ano seguinte, também publicou-a em livro, $O$ Brazil e a educação popular.

Em 1918, outra conferência, pronunciada em Curitiba, foi editada na forma de livro sob o título Pela educação rural. No ano de 1919, outra vez Carneiro Leão reuniu em livro as ideias que defendeu sobre os meios a empregar para a organização da instrução popular no Brasil. Desta vez, compilou sob o título de Problemas de educação os artigos que veiculou na capital federal entre 1914 e 1918 por meio do Jornal do Commercio e do O Paiz. Em cada novo volume, Carneiro Leão opunha suas soluções aos múltiplos problemas educativos do país, registrando aproveitar as questões do momento, as ocorrências diárias, as oportunidades para, assim, conquistar a atenção nacional.

Além disso tudo, em 1921, ele atuou como representante do governo federal na Conferência Interestadual de Ensino Primário e foi o responsável pela sexta tese do conclave: a criação de um Conselho de Educação Nacional. Ao estudar todo o conjunto de suas publicações até então e os Anais da Conferência Interestadual de Ensino Primário, Zentgraf (1994) mostra que Carneiro Leão abordou, entre 1909 e 1921, os temas a partir dos quais organizou a administração da Diretoria Geral de Instrução Pública do Distrito Federal de 1922 a 1926. Aponta que a organização e difusão da instrução popular eram preocupações desde Educação, de 1909 (Zentgraf, 1994).

Quanto à obra O Brazil e a educação popular, Zentgraf (1994) observa as relações que Carneiro Leão estabeleceu entre a criança e a escola e as considerações dele acerca da educação cívica e os processos de educação moral. Do mesmo modo, sublinha que já 
na obra Problemas de educação questões centrais para a compreensão da reforma do ensino na capital federal entre 1922 e 1926 estavam presentes. A aproximação foi provocada pela percepção de que ali a higiene escolar e o saneamento, a reforma dos cursos normais, a educação profissionalizante na escola e a responsabilidade das autoridades do ensino eram pressupostos de qualquer reformulação da estrutura e do funcionamento da escola primária. Principalmente, Zentgraf (1994) entende a ação de Carneiro Leão junto a instrução pública da capital como um esforço no sentido de concretizar o projeto pedagógico que ele concebera e divulgara até 1921 .

Algo semelhante aconteceu com Fernando de Azevedo. Como Carneiro Leão, Azevedo tratou de temas relacionados à educação antes de exercer a direção da instrução pública na capital do país. Sobretudo, ficou conhecido nessa área pelo inquérito que conduziu junto ao jornal paulista $O$ Estado de $S$. Paulo em 1926 sobre a educação pública em São Paulo. Conforme confessou Fernando de Azevedo à época, seus conhecimentos nessa área não ultrapassavam ainda os limites dos estudos da educação física e do ensino da literatura e língua latina.

Segundo conta, depois do convite dos diretores d'O Estado decorreu um mês para que começasse o inquérito. Foi o tempo que Fernando de Azevedo utilizou para buscar informações sobre o assunto. Seguiram-se outros quatro meses até que ele concluísse o inquérito. Dividiu o trabalho em três fases: $1^{\underline{a}}$ ) ensino primário e normal; $2^{\underline{a}}$ ) ensino profissional técnico e $3^{\underline{a}}$ ) ensino secundário e superior. Entrevistou as principais autoridades em ensino do Estado: colheu os depoimentos de Francisco Azzi, Almeida Jr., Renato Jardim, José Escobar, Sud Menucci e Lourenço Filho para organizar a primeira parte. Na segunda parte opinaram Paulo Pestana, Navarro de Andrade, Mello Moraes, Roberto Mange e Paim Vieira. Finalmente, a terceira parte do inquérito foi composta com as respostas de Ruy de Paula Souza, Mário de Souza Lima, Amadeu Amaral, Ovídio Pires de Campos, Raul Briquet, Theodoro Ramos, Reynaldo Porchat e Arthur Neiva.

Fernando de Azevedo concluiu cada parte com dois textos seus, procurando cotejar as ideias substanciais que o inquérito suscitara. O convite para dirigir a Instrução Pública da capital viria em janeiro do ano seguinte, de acordo com o que se sabe, por indicação de Renato Jardim, um dos entrevistados no inquérito. Fernando de Azevedo reconheceu que $O$ Estado de S. Paulo foi a escola onde se preparou para a função: "somente ao ser provido no cargo é que avaliei, em todo o seu alcance, os serviços inestimáveis desse contato a que me forçou a profissão de jornalista, com os fatos e os problemas da educação" (1937, p. XXVI).

Apesar das excelentes reflexões de Irene Cardoso (1982) e de Maria Helena Capelato (1989) acerca das relações de Fernando de Azevedo e do grupo de intelectuais radicados no jornal $O$ Estado de $S$. Paulo com as questões educativas do país à época, há espaço para asserções de tipo mais microscópico. Um indicativo nesse sentido é a avaliação que Fernando de Azevedo faz da importância do inquérito de 1926 para o seu posicionamento em face dos problemas educativos:

nesse inquérito já se encontram, nitidamente definidas, as grandes diretrizes que orientaram daí por diante o meu espírito, quer no exame dos problemas e de suas soluções, quer nas reformas escolares de que tive a iniciativa e a responsabilidade, no Rio e em São Paulo. Nenhuma dessas obras rompeu, como cogumelo, sem raízes, aberto no monturo de 
decadências. Elas desabrocharam, frescas e vivas, de um sistema de ideias que constituíram uma política de educação, coerente e orgânica, e cujas raízes se embebem no húmus fértil daqueles estudos e daqueles debates. (1937, p. XXVIII)

Insistir na aproximação que Azevedo efetua entre as diretrizes definidas pelo inquérito de 1926 ao seu pensamento e o modo como exerceu o cargo de diretor da instrução no Rio, permite apurar ainda um pouco a discussão que as pesquisas de Cardoso e Capelato levantam. De modo geral, o empreendimento suscita referir à ação de um representante do grupo de sociabilidade e do sistema de ideias que elas estudaram. Dessa perspectiva, é útil cotejar os artigos que Fernando de Azevedo escreveu a fim de conduzir e orientar o inquérito e o empreendimento de reforma da instrução carioca para se certificar das semelhanças de ambas as experiências.

Dentre as conclusões do inquérito de 1926 são significativas as que já apontavam para as linhas diretrizes do decreto de reforma da instrução pública da capital federal. Em 1928 a lei do ensino foi apresentada e, por muitos, reconhecida como um plano educativo cientificamente organizado. Nos termos do inquérito de 1926, o decreto n. 3.281 , de 22 de janeiro de 1928, mostrou-se ser aquele instrumento capaz de apontar os ideais impostos por uma nova concepção do social e pelo conhecimento exato do meio.

De fato, em 1928, em conformidade com aquilo que propugnavam as conclusões do inquérito de 1926, Fernando de Azevedo fez da lei de ensino um meio de vincular finalidades sociais e educativas à instrução popular. No mesmo sentido, buscou na organização técnica da direção do ensino "uma força para estimular, coordenar e orientar" (Azevedo, 1937, p. 158), combatendo tanto o isolamento estéril entre a família e a escola, quanto à superstição da uniformidade. De um lado, a reforma de 1928 cuidou de solicitar e atrair a cooperação privada por meio do círculo de país e das caixas e cooperativas escolares. Por outro, içou a formação do caráter e da consciência moral e a orientação vocacional como ideais da educação popular e seus principais deveres. À escola primária cumpria semear esses ideais, ordenando esforços e atividades livres.

Também no tocante ao caráter educativo da escola elementar há similitudes de traços entre o inquérito de 1926 e a reforma de 1928. Várias das iniciativas de Fernando de Azevedo na Diretoria Geral de Instrução do Distrito Federal harmonizaram-se com as perspectivas abertas pelas conclusões do Inquérito d'O Estado de S. Paulo. Publicados em 1929, os programas de ensino para os jardins de infância e escolas primárias tinham tanto em vista a educação moral e higiênica da criança, quanto a sua adaptação social. Sobretudo a idéia de formar professores especialmente preparados para ministrar aulas de educação física e de basear a organização cotidiana das atividades escolares no exercício normal do trabalho em cooperação era tida como soluções educativas face aos novos problemas sociais de então.

A construção dos edifícios escolares, entre 1928 e 1930, obedeceu aos critérios do estilo nacional-brasileiro, num esforço nítido de plasmar nos estabelecimentos de ensino um ambiente de nacionalismo e civismo. Juntamente com o ensino das matérias mais suscetíveis de contribuir para a educação cívica, a arquitetura dos prédios escolares foi considerada, na reforma educativa de 1928, um dos meios que o inquérito de 1926 tomava por eficiente para "levantar a alma das crianças, despertar a energia e o 
sentimento nacional, desenvolver a consciência cívica e entrar com respeitável contingente na obra de nacionalismo" (Azevedo, 1937, p. 164).

Outro traço comum à reforma de 1928 e ao inquérito de 1926 foi o apreço pelos meios com que a ciência poderia auxiliar a obra da educação popular. A divulgação da utilidade do cinema educativo e dos museus escolares para o ensino, entre 1928 e 1930, rendeu eventos como exposições e conferências, bem como a instituição de espaços especializados, como o museu pedagógico central e a filmoteca educativa da Diretoria Geral de Instrução.

Outras similitudes poderiam ainda ser apontadas, abarcando aspectos de ambos os empreendimentos de Fernando de Azevedo. Creio, entretanto, que as esboçadas aqui são suficientes para uma compreensão da maneira como a experiência de reforma da instrução pública do Rio, em 1928, confirmou as posições tomadas por Azevedo em face dos problemas que enfrentara pela primeira vez dois anos antes.

Efetivamente, o trabalho de Fernando de Azevedo no jornalismo lembra o engajamento de Carneiro Leão, que no debate intelectual da década de 1920 do século passado, fixou-se sobre os problemas da educação nacional. Em ambos os casos foi o esforço de crítica da situação educacional do país que impulsionou as carreiras públicas de Carneiro Leão e de Azevedo. Foi esta a primeira etapa da atuação deles como profissionais da educação, a que se seguiu a direção da instrução pública da capital federal. Sobretudo, o exercício da crítica marcou com preocupações práticas e concretas os modos como Carneiro Leão e Fernando de Azevedo constituíram suas propostas de reforma da educação popular.

Embora estudiosos sagazes das teorias educacionais e da sociologia, interessaramse pelos práticos, por aqueles que no país ou no exterior testemunhavam ou experimentavam novos métodos de ensino e de organização dos fazeres escolares. Nesse sentido, são esclarecedoras as referências que constam dos textos publicados por Carneiro Leão, entre 1922 e 1926, e por Fernando de Azevedo, de 1927 a 1930. As listas são ecléticas e a primeira vista sem muita unidade, mas possuem alguns nomes em comum: Montessori, Decroly, Kerschensteiner e Sussekind de Mendonça. As diferenças confundem-se com os colaboradores mais próximos de cada uma das reformas do ensino. Por um lado, Manoel Bomfim, Delgado de Carvalho, Deodato de Morais e Carlos Porto Carrero trabalharam juntamente com Carneiro Leão para a aplicação de testes pedagógicos e psicológicos nas escolas da capital e na elaboração de cursos de formação. De outro lado, Fernando de Azevedo buscou em Lourenço Filho, Vicente Licinio Cardoso e Francisco Venâncio Filho divulgadores dos mais atuais métodos educativos. Ainda fizeram parte do horizonte de referências dos textos de Fernando de Azevedo autores como Durkheim, Dewey, Lunatcharsky e Hartman.

Entre o repertório de autores que as publicações da Diretoria de Instrução veicularam entre 1922 e 1930, as principais referências dão conta de explicitar os propósitos práticos da obra de reforma do ensino à época. Principalmente são vestígios das veredas pelas quais seguiu a edição dos programas de ensino, do Boletim da Educação Pública ou dos cursos de formação em serviço do magistério, talhando o apelo das realidades correntes que atingia a Fernando de Azevedo e Carneiro Leão, desde as suas primeiras críticas ao estado da educação popular do país. 
A época que atuaram na Diretoria Geral de Instrução do Distrito Federal, as carreiras de Carneiro Leão e Fernando de Azevedo, como profissionais da educação, derivavam menos de um sistema ou teoria, que da prática com assuntos educacionais. Ambos, então, já revelavam conhecer os problemas da educação popular no Brasil, as instâncias administrativas competentes e os diferentes níveis das questões do ensino público. Ainda que um publicista e outro jornalista, atuaram pela análise comparada e do cotejo de opiniões. Tanto Carneiro Leão, na tribuna ou na imprensa, quanto Fernando de Azevedo, n'O Estado de S. Paulo, exerceram a crítica da mentalidade, dos dispositivos e da política de ensino que dominavam a educação pública do país. Então já haviam se aplicado em controlar e decompor os instrumentos do ensino, em consultar os textos que tinham servido às informações correntes, em analisar com alguma profundidade as questões da educação pública.

A importância desse exercício crítico minucioso, centrado na observação dos traços típicos do funcionamento escolar e no estudo, para Carneiro Leão e Fernando de Azevedo mostrou-se ser a atitude mental que fomentou quando eles foram providos no posto de direção do ensino da capital. Ainda que passando da seara da crítica para a realização prática, ambos conduziram reformas no ensino público decifrando indícios, articulando dispositivos e instrumentos, recompondo informações e comunicando, concretamente, de maneira ordenada e contínua. Nesse sentido, as reformas da educação da capital federal, entre 1922 e 1930, permitem uma análise que deixa ver como funcionou a atitude mental, cujas características apenas procurei sugerir.

Principalmente Carneiro Leão, entre 1922 e 1926, e Fernando de Azevedo, de 1927 a 1930, dominaram o comando da Diretoria Geral da Instrução Pública por meio da prática de técnicas do ordenamento jurídico, dos procedimentos administrativos e da produção intelectual. A decomposição dessas três instâncias do exercício do poder naquela repartição da Prefeitura é, meramente, para tornar mais conveniente à análise tratar das atribuições do diretor geral da instrução pública na capital federal. Serve para expor algo sobre os âmbitos de atuação de Antônio Carneiro Leão e Fernando de Azevedo na Diretoria Geral de Instrução Pública.

\section{A produção intelectual e o exercício da crítica}

Já são bastante estudadas as manipulações da prática e do discurso jurídicos promovidas pelas reformas educacionais no país. Sobretudo as pesquisas de Clarice Nunes $(1992,1993,1996)$, nesse âmbito auxiliam o mapeamento das principais questões, mostrando que o impulso realizador e organizador daquele período buscou, na revisão e criação da legislação escolar, as condições para se institucionalizar. Os estudos que Nunes desenvolveu acerca da autoridade jurídica de Carneiro Leão, Fernando de Azevedo e Anísio Teixeira nas instâncias administrativas do poder executivo do Rio de Janeiro revelam aspectos operacionais dessas práticas.

Segundo os argumentos de que esses estudos se utilizam, o saber jurídico foi o veículo para a afirmação de uma determinada mentalidade, que estava sendo formada, de fato, nas lutas sociais do período. Servindo para delimitar um conjunto de soluções jurídicas para problemas postos pelo funcionamento escolar, a prática e o discurso legislativo configuraram exigências de ingresso no magistério, condições de trabalho nas 
escolas, espaços de atuação na educação e um valor social para diferentes grupos profissionais ligados à educação (Nunes, 1992).

Com conteúdos práticos a legislação codificou espaços, saberes e poderes para o processo de autonomização do campo educacional, que garantiu a sua especificidade e criou o entendimento de que ele não se configurava como extensão do campo religioso, médico ou jurídico (Nunes, 1996). Ainda conforme as reflexões de Clarice Nunes (1992), as manipulações da prática e do discurso jurídico foram artifícios, tanto para consolidar grupos profissionais, quanto para criar a imagem das instituições instituídas. Nesse sentido, Nunes (lbid.)) tem muita razão em considerar as insistentes mudanças na legislação de ensino da época como a tradução de uma multiplicidade não só de visões de mundo, mas de interesses em disputa.

Também há um acúmulo significativo de estudos a respeito das ideias pedagógicas, as quais se expressaram por meio das reformas do ensino público na capital entre 1922 e 1930.

As pesquisas de Zentgraf (1994) e Mendonça (1997) focalizam as concepções de Carneiro Leão sobre educação e organização do sistema de ensino, bem como registram aspectos do seu pensamento e realizações. Principalmente no que tange a história intelectual, o esforço de Zentgraf (1994), em analisar a produção editada de Carneiro Leão no período, resultou num esquema elucidativo do repertório de referências desse reformador. Segundo suas conclusões de estudo, as ideias do diretor de instrução da capital federal, entre 1922 e 1926, o aproximavam do pensamento inovador liberal. Zentgraf (lbid.) argumenta que havia, na produção intelectual de Carneiro Leão à época, uma forte influência das concepções sociológicas de educação de Durkheim, da escola progressista de Dewey, da escola do trabalho de Kerchensteiner e do projeto de educação de Ruy Barbosa.

Igualmente relevantes para os estudos sobre a produção intelectual de Fernando de Azevedo, esses autores constituem um repertório de referências no seu projeto de reforma. No caso, todavia, a historiografia perspectivou, de diversos ângulos, o ideário reformista articulado na Diretoria Geral de Instrução de 1927 a 1930. Por um lado, Rato (1980), Cardoso (1982) e Capelato (1989), entre outros pesquisadores, destacam as ligações de Azevedo com o tipo de liberalismo que o jornal O Estado de $S$. Paulo então representava. Sobretudo, tratam-se de estudos atentos ao ambiente político de configuração do pensamento daquele reformador. De outra parte, Pagni (2004) e Rocha (2004) sustentam que a reforma da instrução, entre 1928 e 1930, tem bases numa revisão da compreensão de Durkheim de escola reprodutora da cultura da sociedade expressa pelo Estado.

Atentos aos resíduos românticos que Azevedo consubstancia na sua produção intelectual, ambos os pesquisadores reúnem indícios da influência das fontes alemãs, tais como Fichet, Hegel e Kerschensteiner. Outros estudos ainda (Mendes, 1987; Penna, 1987) acusam a incongruência das referências que marcaram o pensamento de Fernando de Azevedo. Precisamente nesse sentido, Mendes (Ibid.) e Penna (lbid.) percebem as dificuldades de se fazer coerente um ideário haurido no positivismo de Durkheim, no pragmatismo de Dewey e na razão kantiana.

Por outro lado, há estudos que tomam em conjunto o ideário reformista dos anos 1920 e 1930 na educação. Nesse caso, a reflexão mais conhecida talvez ainda seja a de Hist. Educ. [Online] Porto Alegre v. 17 n. 41 Set./dez. 2013 p. $43-57$ 
Carlos Roberto Jamil Cury (1978) sobre a ideologia de católicos e liberais. No que se refere aos liberais, Cury observou, na ideologia dos pioneiros da educação nova, um momento de compromisso entre diferentes versões ideológicas presentes nos reformadores. Ainda assim, sobressaem a comunhão de propósitos e os pressupostos sustentadores da unidade de posições dos educadores liberais do ensino. Isso ocorre de tal modo que a análise opera por meio de ideias-força, reunindo por princípios comuns as concepções educacionais desse grupo. Assim, o humanismo científico-tecnológico, a utilização de uma linguagem científica e sociológica, a ênfase nos métodos ativos de ensino, o papel essencial e primordial do Estado na organização da escola pública e os princípios de obrigatoriedade, gratuidade e laicidade da educação pública identificam o programa de ação dos reformadores (Cury, 1978).

Em sentido idêntico, Dermeval Saviani (1983, 1995) utiliza-se da designação "concepção humanista moderna" (p. 20) para abranger correntes de ideias associadas ao escolanovismo. Aproxima o grupo liberal de reformadores do ensino da década de 1920 das proposições pragmatistas, vitalistas, historicistas e mesmo existencialistas de educação. Portanto, como Jamil Cury, Saviani (1995) reconhece diferenças entre as vertentes que reúne sobre a expressão humanista moderna. Contudo, ainda uma vez, as suas análises reduzem estas diferenças a um programa comum de ação e ideias. Trabalhos de pesquisa mais recentes (Brandão, 1999; Pagni, 2000; Rocha, 2004; Warde, 2004) têm matizado as principais divergências de procedimentos e de pensamento no interior do grupo identificado como de educadores liberais, em relação ao qual estão ligadas as biografias de Carneiro Leão e Fernando de Azevedo.

Não obstante os resultados desses esforços, o compromisso político com a escola pública gratuita, obrigatória e laica localiza bem as ações de intelectuais como Carneiro Leão e Fernando de Azevedo no interior do grupo de educadores liberais. Igualmente, a preferência pela linguagem científica e pelos artifícios da racionalização dos processos educativos baliza a compreensão das afinidades entre as diferenças de concepção política que o grupo liberal de educadores conjugou.

Já no caso dos procedimentos administrativos de reforma do ensino, a historiografia basicamente informa sobre o aparecimento dos profissionais da educação. Conforme o exposto no capítulo inicial, essa nova categoria profissional enquadrava homens públicos e intelectuais que, ao mesmo tempo, eram educadores. Ainda que assim, esse foi o domínio de especializações em assuntos educacionais de parte dos intelectuais envolvidos com as reformas do ensino. Portanto, não há razões para discordar da alcunha de técnicos com que a imprensa carioca os distinguiu.

De fato, Carneiro Leão e Fernando de Azevedo assumiram a direção da instrução legitimados pelo que haviam publicado sobre educação; foram tidos como autoridades no conhecimento da questão. Tampouco existem reparos a fazer na discussão historiográfica sobre os profissionais da educação. Significativamente, as divergências que circunstanciam as teses de Nagle (1974) sobre a tecnicização do campo educacional e de Marta Carvalho (1989b) acerca da politização em outros termos, configuram o tema do status profissional dos agentes da renovação escolar nos anos 1920 como problemática para pesquisa de modo exemplar. O que há, sobretudo, é uma atribuição do poder de controle da Diretoria Geral de Instrução que ainda cabe indagar. Por isso, talvez seja 
esclarecedor discutir os expedientes que Carneiro Leão e Fernando de Azevedo utilizaram para administrar a educação pública.

Entre 1922 e 1926 Carneiro Leão dirigiu a reforma do ensino público da capital federal, segundo diretrizes que construiu para uso próprio. Os seus relatos a respeito ajudam a recompor a sequência de ações que então articulou. Primeiro, Carneiro Leão organizou cursos de formação para o magistério em serviço. No discurso de abertura do curso inicial, informou do objetivo de "assegurar imediata experimentação na conquista e nos cursos de aperfeiçoamento dos professores em atividade" (Carneiro Leão, 1942, p. 73). Depois, foi a vez das iniciativas que visavam à redistribuição do magistério pelas escolas da capital. Fundamentalmente elas envolveram providências de incentivo à regência nas classes de alfabetização e de regulamentação da designação das aulas, impedindo a regência de turmas com meia dúzia de alunos (Carneiro Leão, 1926).

Seguiu-se a organização dos serviços de secretaria. Segundo registrou Carneiro Leão (lbid.), procedeu-se a elaboração de toda estatística e escrituração escolar na $3^{\mathrm{a}}$ seção da Diretoria de Instrução, para descentralizar os serviços do gabinete do diretor. Ainda com a finalidade de otimizar o expediente administrativo da Diretoria de Instrução, Carneiro Leão fez compilar toda a legislação vigente do ensino num digesto, organizado para facilitar a consulta.

Também foram mudados os parâmetros de classificação do professorado na carreira do magistério. Entre 1923 e 1925 os critérios de promoção incluíram a avaliação da aptidão pedagógica, do zelo pela escola e pelo ensino, da pontualidade e assiduidade do docente, do exercício em zona rural (Ibid.). Enfim, as atividades de pesquisa, formação e os serviços extraordinários, invariavelmente, eram organizados por meio do trabalho comissionado. Assim, os programas de ensino, os cursos de formação em serviço, a classificação dos quadros do magistério, o Digesto da instrução foram tarefas realizadas por comissões de trabalho.

Acerca do que Carneiro Leão percebeu como necessário mudar, mas não pôde reformar, deixou sugestões. Dentre elas foi, particularmente, circunstanciada a proposta de remodelação da Diretoria Geral de Instrução Pública. Sem autorização para a reforma dos serviços de educação, Carneiro Leão deu registro ao que pensou serem melhoramentos indispensáveis ao êxito administrativo da educação. Fundamentalmente, resultado da crítica do diretor de instrução à organização do expediente do seu gabinete, as sugestões quanto aos serviços de secretaria revelaram-se propostas de racionalização técnica-burocrática. Basicamente, Carneiro Leão pleiteava uma organização administrativa que tivesse um regulamento capaz de distribuir o serviço, determinar atribuições, definir responsabilidades e estruturar o trabalho geral. Buscava solução para um regime que centralizava as responsabilidades de despacho, arquivamento e registro no gabinete do diretor geral de instrução.

Sua proposta era criar, na Diretoria Geral de Instrução, subdiretorias, nos moldes das que já funcionavam na Diretoria de Obras e na de Fazenda, para desafogar os afazeres do diretor geral. Carneiro Leão compreendia a necessidade do gabinete da direção acumular as funções burocráticas e técnicas do ensino, mas advertia sobre a necessidade de distribuir esses serviços por repartições mais especializadas.

Entre 1927 e 1930 foi a vez de Fernando de Azevedo organizar uma nova reforma do ensino público da capital federal. Segundo o que ele havia constituído como diretriz de Hist. Educ. [Online] Porto Alegre v. 17 n. 41 Set./dez. 2013 p. $43-57$ 
ação, a remodelação da Diretoria Geral de Instrução seguiu as indicações de Carneiro Leão. De fato, em 1928 a nova lei de ensino instituiu a subdiretoria técnica e a subdiretoria administrativa da instrução pública. Em 1927, no discurso de posse no cargo de diretor da instrução, Fernando de Azevedo (1929,) adiantou outros aspectos do plano de reorganização do ensino que, no ano seguinte, constituíram os dispositivos de lei da reforma da instrução.

$\mathrm{Na}$ ocasião, anunciou que reformaria o ensino normal para aproveitar melhor os professores da Escola Normal do Distrito Federal, organizaria o ensino primário gratuito e obrigatório e anexaria ao maior número possível de escolas primárias o ensino técnico elementar pré-vocacional. Revelou, ainda, ter o propósito de eliminar instituições ociosas, remodelar a inspeção escolar e ajustar o ensino técnico e profissional ao sistema geral de educação. Fernando de Azevedo também se comprometeu com o reestabelecimento do almoxarifado privativo da instrução pública e com a construção e instalação de prédios para as escolas.

Até 1930 a Diretoria Geral de Instrução Pública realizou muito disso tudo. Durante o quadriênio de gestão de Fernando de Azevedo, a instrução pública da capital federal somou nove novos edifícios escolares e um prédio para servir como almoxarifado, fez do último ano primário um curso pré-vocacional e baixou programas que predeterminavam a especialização das escolas profissionais. Ocorreram concursos para docentes na Escola Normal, com vistas a solucionar a questão do melhor aproveitamento dos seus cento e oitenta professores.

Se, mesmo antes de um contato de fato com o ensino do Rio de Janeiro, pareceu lícito ao novo diretor geral da instrução traçar um programa de ideias é porque já tinha informações acerca da organização dele. Há nos escritos de Fernando de Azevedo passagens que aludem a leitura das análises de seus antecessores sobre a situação do aparelho de ensino da capital. Logo no discurso de posse, toda a sua crítica ao estado de funcionamento da instrução pública da capital apoiou-se no relatório que Renato Jardim havia apresentado ao governador da cidade.

Naquele momento, revelou-se familiarizado com a leitura de monografias e exposições exaustivas sobre os problemas educativos da capital federal, entre as quais as de Carneiro Leão e Renato Jardim (Azevedo, 1929). Encontra-se em outros discursos de Azevedo a evocação dessas leituras. Sobretudo, Fernando de Azevedo (Ibid.) avaliou que Carneiro Leão pôs em foco os problemas educativos, concebendo um conjunto de elementos "indispensáveis às realizações coordenadas segundo um plano seguro e uniforme". A Renato Jardim atribuiu "uma observação exata e paciente" (Ibid., p. 27) na apreciação dos fatos e instituições do ensino carioca. Em razão disso, Fernando de Azevedo reconheceu que o empreendimento de reforma da instrução pública foi preparado há anos:

Não será preciso, por isto, um reformador de rasgos originais. Bastará apurar os ouvidos para auscultar as necessidades, os defeitos e as aspirações que estão na consciência de todos e meter mãos à obra hercúlea de reconstrução. O próprio ambiente já está preparado e agitado para uma grande reforma. (1929, p. 23)

A leitura, enfim, fornece firmes diretrizes de trabalho para Fernando de Azevedo quando inicia na Diretoria de Instrução do Distrito Federal. Antes mesmo da verificação

\begin{tabular}{|c|c|c|c|c|c|}
\hline Hist. Educ. [Online] & Porto Alegre & v. 17 & n. 41 & Set./dez. 2013 & p. 43-57 \\
\hline
\end{tabular}


pessoal dos problemas educativos da cidade, a leitura de monografias e exposições a respeito da instrução pública carioca determinou as bases do empreendimento de reforma iniciado em 1927. Apropriadamente, a observação minuciosa, centrada na crítica da situação existente permitiu, tanto retificar funcionamentos já tradicionais, quanto reivindicar novas instituições na administração central do ensino.

Não só o conhecimento exaustivo da matéria, mas, principalmente, a perícia que exige o exercício da crítica minuciosa, pareceram decisivos para o modo como Carneiro Leão e Fernando de Azevedo dirigiram a instrução pública do Rio de Janeiro. Parte dos meios de que cada um deles se utilizou quando iniciaram na Diretoria de Instrução tem, a meu ver, muito da perícia com a qual eles exerceram a crítica do sistema de educação então vigente no país. Sobretudo, à época, a produção textual, a solicitação pública de sugestões, o debate provocado na imprensa, mobilizou um pouco disso.

Sob essa perspectiva, as reformas da educação da capital federal, entre 1922 e 1930, resultaram também da perícia da ação de Carneiro Leão e Fernando de Azevedo na Diretoria Geral de Instrução. Elas fugiram às facilidades abertas pela complacência das câmaras legislativas e ao sigilo das elaborações burocráticas para expor, em público, princípios e objetivos precisos. Em decorrência, o principal das discussões em torno das reformas do ensino na capital federal atuou, definitivamente, na posterior definição de políticas públicas para a educação. Se, então, esta experiência foi fundamental para a construção de uma nova concepção de educação no país, seu impacto vem sendo reinterpretado, na mesma medida em que questões como a da adaptação das escolas às ideias modernas da educação (Hanna Mate, 2002; Vidal, 2000) e a da duração da memória que se construiu sobre o movimento educacional (Carvalho, 1989b) tornaram-se objeto de reflexão da historiografia.

Por um lado, o que se assinala é que as estratégias textuais e editoriais de difusão das iniciativas de reforma do ensino no Distrito Federal, as quais recorreram Carneiro Leão e Fernando de Azevedo, foram recebidas pelo público como um sinal de mudança, afirmando-se como paradigma da modernidade pedagógica. Por outro, mostrou-se que o trabalho de muitos intelectuais, entre os quais o próprio Fernando de Azevedo, retomou e consolidou uma história-memória do movimento educacional.

Dessa forma, compreendeu-se o impacto da prática da geração de educadores que atuou na Diretoria Geral de Instrução da capital durante a década de 1920. Carvalho (1988; 1989), Vidal (2000) e Hanna Mate (2002), mas também Rocha (2004) e Nunes (1996) abriram perspectivas para ver que as reformas educativas da época, na cidade do Rio de Janeiro, funcionaram como instâncias de disseminação de instrumentos novos de política de educação. Entre os principais deles existiram procedimentos discursivos, apropriações de frentes institucionais abertas por outros e estratégias de contestação dos modelos de trabalho vigentes na educação pública, que sugerem haver muito da peritagem na administração das reformas do ensino na capital federal. Em parte, o que então se traduziu em realizações nas reformas do ensino, resultou da capacidade dos diretores da instrução pública de acionar meios e práticas capazes de refazer os procedimentos padronizados e rotineiros das organizações educativas. 


\section{Referências}

AZEVEDO, Fernando de. A reforma do ensino no Districto Federal: discursos e entrevistas. São Paulo: Melhoramentos, 1929.

AZEVEDO, Fernando de $A$ educação pública em S. Paulo: problemas e discussões: inquérito para o Estado de S. Paulo em 1926. São Paulo: Companhia Editora Nacional, 1937.

BRANDÃO, Zaia. Paschoal Lemme, marxista e pioneiro da educação nova. In: FREITAS, Marcos Cezar de. Memória intelectual da educação brasileira. Bragança Paulista: Edusf, 1999, p. 49-61.

CAPELATO, Maria Helena. Os arautos do liberalismo: imprensa paulista, 1920-1945. São Paulo: Brasiliense, 1989, p. 140-149.

CARDOSO, Irene. A universidade da comunhão paulista. São Paulo: Cortez, 1982.

CARNEIRO LEÃO, Antônio. O Brazil e a educação popular. Rio de janeiro: Typ. do Jornal do Commercio, 1917.

CARNEIRO LEÃO, Antônio. O ensino na capital do Brasil. Rio de janeiro: Typ. do Jornal do Commercio, 1926.

CARNEIRO LEÃO, Antônio. Planejar e agir. Rio de Janeiro: Jornal do Commercio, 1942.

CARVALHO, Marta Maria Chagas de. A escola e a República. São Paulo: Brasiliense, 1989a.

CARVALHO, Marta Maria Chagas de. Notas para reavaliação do movimento educacional brasileiro (1920-1930). Cadernos de Pesquisa, São Paulo, n. 66, 1988, p. 4-11.

CARVALHO, Marta Maria Chagas de. O novo, o velho, o perigoso: relendo "A Cultura Brasileira". Cadernos de Pesquisa, São Paulo, n. 71, 1989b, p. 29-35.

CURY, Carlos R. Jamil. Ideologia e educação brasileira: católicos e liberais. São Paulo: Cortez; Campinas: Autores Associados, 1978.

HANNA MATE, Cecília. Tempos modernos na escola: os anos 30 e a racionalização da educação brasileira. Bauru: Edusc; Brasília: Inep, 2002.

MENDES, Dumerval Trigueiro. Prefácio. In: PENNA, Maria Luiza. Fernando de Azevedo: educação e transformação. São Paulo, Perspectiva, 1987, p. XIII-XIX.

MENDONÇA, Sandra Cabral. Carneiro Leão: sonhos e frustrações na Diretoria de Instrução Pública do Distrito Federal (1922-1926). Rio de Janeiro: PUCRJ, 1997. $70 f$. Dissertação (mestrado em Educação). Faculdade de Educação, Pontifícia Universidade Católica do Rio de Janeiro.

NAGLE, Jorge. Educação e sociedade na Primeira República. São Paulo: EPU; Rio de Janeiro: Fundação Nacional do Material Escolar, 1974.

NUNES, Clarice. A escola redescobre a cidade: reinterpretação da modernidade pedagógica no espaço urbano carioca (1910-1935). Niterói: UFF, 1993. 227f. Tese (concurso para professor titular em História da Educação). Departamento de Fundamentos Pedagógicos, Universidade Federal Fluminense.

NUNES, Clarice. Cultura escolar, modernidade pedagógica e política educacional no espaço urbano carioca. In: HERSHMANN, Micael (org.). Missionários do progresso. Rio de Janeiro: Diadorim, 1996, p. 115-224.

NUNES, Clarice. História da educação brasileira: novas abordagens de velhos objetos. Teoria \& Educação, n. 6, 1992, p. 151-182.

\begin{tabular}{|c|c|c|c|c|c|}
\hline Hist. Educ. [Online] & Porto Alegre & v. 17 & n. 41 & Set./dez. 2013 & p. 43-57 \\
\hline
\end{tabular}


PAGNI, Pedro Angelo. Do Manifesto de 1932 à construção de um saber pedagógico: ensaiando um diálogo entre Fernando de Azevedo e Anísio Teixeira. ljuí: Unijuí, 2000.

PENNA, Maria Luiza. Fernando de Azevedo: educação e transformação. São Paulo, Perspectiva, 1987.

RATO, Catherine Laurence Marguerite Carrieres. Fernando de Azevedo: sua contribuição à educação brasileira. Rio de Janeiro: UFRJ, 1980. 130f. Dissertação (mestrado em Educação). Faculdade de Educação, Universidade Federal do Rio de Janeiro.

ROCHA, Marlos Bessa Mendes da. Matrizes da modernidade republicana: cultura política e pensamento educacional no Brasil. Campinas: Autores Associados; Brasília: Plano, 2004.

SAVIANI, Dermeval. A filosofia da educação e o problema da inovação em educação. In: GARCIA, Walter Esteves. Inovação educacional no Brasil: problemas e perspectivas. Campinas: Autores Associados, 1995, p. 17-31.

SAVIANI, Dermeval. Educação e democracia. São Paulo: Cortez/Autores Associados, 1983.

VIDAL, Diana. Escola nova e processo educativo. In: LOPES, Eliane Marta Teixeira; FARIA FILHO, Luciano Mendes; VEIGA, Cynthia Greive (org.). 500 anos de educação no Brasil. Belo Horizonte: Autêntica, 2000, p. 497-517.

WARDE, Mirian Jorge. Legado e legatários: questões sobre o Manifesto dos pioneiros da educação nova. In. XAVIER, Maria do Carmo (org.). Manifesto dos pioneiros da educação: um legado educacional em debate. Rio de Janeiro: FGV, 2004, p. 221-240.

ZENTGRAF, Maria Christina Santos Rocha. Projetos pedagógicos na Primeira República Brasileira: a contribuição de Antônio Carneiro Leão. Rio de Janeiro: UFRJ, 1994. 210 f. Tese (doutorado em Educação). Faculdade de Educação, Universidade Federal do Rio de Janeiro.

ANDRÉ LUIZ PAULILO é professor na Universidade Estadual de Campinas, doutor em Educação pela Universidade de São Paulo.

Endereço: Rua Bertrand Russel, 801 - Cidade Universitária Zeferino Vaz - 13083865 - Campinas - SP - Brasil.

E-mail: paulilo@unicamp.br.

Recebido em 21 de março de 2013.

Aceito em 14 de junho de 2013. 